\title{
CARACTERÍSTICAS DE GRANOS Y TORTILLAS DE MAÍCES DE ALTA CALIDAD PROTEÍNICA DESARROLLADOS PARA LOS VALLES ALTOS CENTRALES DE MÉXICO
}

\section{CHARACTERISTICS OF KERNELS AND TORTILLAS OF QUALITY PROTEIN MAIZE DEVELOPED FOR THE CENTRAL HIGHLANDS OF MÉXICO}

\author{
Ma. Gricelda Vázquez Carrillo ${ }^{1 \star}$, Hugo Mejía Andrade ${ }^{2}$, Casiano Tut Couoch ${ }^{2}$ y Noel Gómez Montiel ${ }^{2}$
}

\begin{abstract}
${ }^{1}$ Laboratorio de Calidad de Maíz, Campo Experimental Valle de México, Instituto Nacional de Investigaciones Forestales, Agricolas y Pecuarias (INIFAP). Km. 38.5 Carretera México-Texcoco. 56230, Chapingo, Estado de México. Tel. 01(595)9521500, Ext. 5211. ${ }^{2}$ Campo Experimental Valle de México, INIFAP. Carretera Los Reyes-Texcoco, Km. 13.5. 56250, Coatlinchán, Texcoco, Estado de México.

*Autor para correspondencia (gricelda_vazquez@yahoo.com)
\end{abstract}

\section{RESUMEN}

En esta investigación se determinó la influencia de la localidad en la calidad comercial, proteínica, de nixtamalización y tortillera del grano de cuatro híbridos de maíz (Zea mays L.) de alta calidad proteínica ('H-143C, 'H-145C, 'H-147C' y 'H-149C'). Estos híbridos se cultivaron en Santa Lucía, Estado de México (SLM) y en Tecamachalco, Puebla (TP), y como testigos se usaron maíces de endospermo normal, 'Halcón' y 'H-151' respectivamente. Los resultados se analizaron bajo un diseño de bloques completos al azar. La localidad y el híbrido afectaron el tamaño, la dureza, el color y la calidad proteínica de los maíces de alta calidad proteínica. En SLM los granos fueron de dureza intermediasuave, lo que se asoció con porcentajes de proteína de 10.2 a $11.5 \%$, cuyos contenidos de lisina y triptófano cubren de 85 a más de $100 \%$, respectivamente, del requerimiento de niños entre 3-10 años de edad. Los mismos híbridos sembrados en TP fueron de grano duro y con más aceite que los de SLM, y sus tortillas contenían menos proteína que los cultivados en SLM. El nixtamal de los maíces de SLM requirió menos tiempo de cocción y retuvo más pericarpio $(51.5 \%)$ que los de TP. Sus tortillas tenían más humedad $(43.0 \%)$ y requirieron menor fuerza de punción para romperse $\left(215 \mathrm{~g}_{\mathrm{f}}\right)$ que las de TP. Destacó el híbrido 'H-143C' cultivado en SLM, por su mayor rendimiento de masa y tortillas, así como su mejor calidad proteínica.

Palabras clave: Zea mays, lisina, maíz de alta calidad proteínica, tortillas, triptófano.

\section{SUMMARY}

In this research we determined the influence of location on the commercial quality, protein, nixtamalization and tortillera of the kernels produced by four quality protein maize (Zea mays $\mathrm{L}$.) hybrids ('H-143C', 'H-145C', 'H-147C' and 'H-149C'). These hybrids were grown in St. Lucía, México State (SLM) and Tecamachalco, Puebla (TP), using as controls of normal endosperm the hybrids 'Halcón' and ' $\mathrm{H}$ 151', respectively. Evaluations were made on kernel and tortillas, and included physical, chemical and nixtamalero-tortilleras characteristics. The results were analyzed under a randomized complete block design. Both location and hybrid affected the size, hardness, color and protein quality of the quality protein maize hybrids. In SLM, the kernels were of medium-soft hardness with protein contents of 10.2-11.5\%; their lysine and tryptophan contents can cover from 85 to more than $100 \%$, respectively, of the requirements of children between 3-10 years old. The hybrids planted in TP had harder kernels with more oil and their tortillas contained significantly less protein than those grown in SLM. The nixtamal of the SLM required less cooking time and retained more pericarp $(51.5 \%)$ than that of TP. The SLM tortillas had more moisture $(43.0 \%)$ and required less punction force $\left(215 g_{f}\right)$ than the TP tortillas. The hybrid 'H-143C' grown in SLM stood out for its greater masa and tortilla yield, as well as its better protein quality.

Index words: Zea mays, lysine, quality protein maize, tortillas, tryptophan.

\section{INTRODUCCIÓN}

Las condiciones agroclimáticas vigentes en los Valles Altos del Centro de México (> $2200 \mathrm{msnm}$ ), que incluye los estados de México, Puebla, Hidalgo, Tlaxcala, Querétaro, Michoacán y el Distrito Federal, son favorables para el desarrollo del cultivo de maíz aunque los rendimientos promedio son menores a $4.5 \mathrm{t} \mathrm{ha}^{-1}$ (Ávila et al., 2009). En esta región, $70 \%$ de la producción proviene de maíces criollos y se destina al autoconsumo (Polanco y Flores, 2008), principalmente en forma de tortilla. Debido a que los maíces de endospermo normal son deficientes en los aminoácidos esenciales lisina y triptófano (Serna et al., 2008) y las tortillas son alimento de la canasta básica mexicana, se les relaciona con los problemas de desnutrición que sufren entre 30 y 50 \% de los niños menores de cinco años (Chávez y Muñoz, 2004).

Desde hace 30 años se han desarrollado híbridos de maíz de alta calidad proteínica (ACP), derivados de trabajos realizados entre el Centro Internacional de Mejoramiento de Maíz y Trigo (CIMMYT) y el Instituto Nacional de Investigaciones Forestales, Agrícolas y Pecuarias (INIFAP). Los primeros maíces ACP que se liberaron fueron los 
adaptados a regiones tropicales y subtropicales, que rinden de 7 a 13 t ha $^{-1}$ (Melesio et al., 2008). Posteriormente se desarrollaron híbridos de maíces ACP para clima templado, como los Valles Altos de México, a fin de elevar el rendimiento y mejorar la calidad de las tortillas que con ellos se elaboren, y así mejorar también la nutrición humana, en especial en los sectores más desprotegidos.

La calidad comercial del grano de maíz para consumo humano está declarada en la norma MNX-034 (2002), que incluye los procesos de fabricación de harina nixtamalizada y la elaboración de masa y tortilla. En ambos casos las industrias prefieren maíces con las siguientes características: peso hectolítrico $\geq 74 \mathrm{~kg} \mathrm{hL}^{-1}$, humedad del nixtamal entre 36 y $42 \%$, índice de flotación $\leq 40 \%$, pericarpio remanente $<2 \%$ y pérdida de sólidos $<5 \%$.

La mayor parte de las investigaciones sobre híbridos de maíz ACP se ha enfocado a evaluar la influencia del ambiente sobre el rendimiento en campo y otras características agronómicas (Melesio et al., 2008). Además, se sabe que el genotipo y el ambiente afectan las propiedades físicas del grano y la calidad de las tortillas, como se ha demostrado en maíces de endospermo normal (Zepeda et al., 2009). Sin embargo, poco se ha estudiado el efecto ambiental sobre la calidad proteínica y tortillera de los granos de maíz ACP. Así el objetivo de la presente investigación fue evaluar la influencia de la localidad de siembra en la calidad comercial, proteínica, de nixtamalización y tortillera del grano de cuatro híbridos de maíz de alta calidad proteínica adaptados a los Valles Altos de México.

\section{MATERIALES Y MÉTODOS}

Los experimentos de campo se llevaron a cabo durante 2003, en condiciones de riego y con una dosis de fertilización de $120 \mathrm{~N}-60 \mathrm{P}-00 \mathrm{~K}$, en los campos experimentales de Santa Lucia, municipio de Coatlinchan, Estado de México (SLM) y en Tecamachalco, en el Estado de Puebla (TP). En SLM el clima es templado húmedo, con temperatura media anual de $16.4{ }^{\circ} \mathrm{C}$ y precipitación de $620 \mathrm{~mm}$, donde los meses de julio y agosto son los más lluviosos, con altitud de $2240 \mathrm{~m}$; donde predominan los suelos cambisoles de textura fina y media. En SLM la siembra se hizo el 20 de mayo, con semillas híbridas que se obtuvieron mediante cruzamientos planta-planta por polinización manual. El sitio TP está ubicado a $2013 \mathrm{msnm}$, y su clima es templado semiseco, con temperatura media anual de $16.2{ }^{\circ} \mathrm{C}$ y precipitación de $476 \mathrm{~mm}$, con junio como el mes más lluvioso; en este lugar predominan los suelos arenosos profundos. En TP se sembró el 15 de junio, y el lote se aisló con cuatro surcos de bordo. Los muestreos de grano se hicieron en el centro de la parcela, ya que la polinización fue abierta.
Los híbridos de maíz ACP evaluados fueron ' $\mathrm{H}-143 \mathrm{C}$ ', 'H-145C', 'H-147C' y 'H-149C', todos constituidos de cruzas trilineales de maduración tardía, en las que se combinaron líneas convertidas a ACP del programa de Valles Altos del INIFAP de alta aptitud combinatoria general (ACG) y líneas ACP proporcionadas por el CIMMYT. Como testigos de endospermo normal se usaron los híbridos comerciales 'Halcón' en SLM y 'H-151' en TP, los cuales se seleccionaron por ser materiales de alto rendimiento probado en estas localidades.

\section{Análisis físicos y químicos}

Se hicieron en el Laboratorio de Calidad de Maíz del INIFAP. Las variables medidas fueron: peso de 100 granos; índice de flotación (IF), que es una medida indirecta de la dureza del grano (Salinas y Vázquez, 2006); peso hectolítrico (Método 84-10; AACC, 2000). El color de grano se midió con un reflectómetro Agtron (Md. M300A), método 14-30 (AACC, 2000), operado en modo verde y calibrado con los mosaicos 10 y 63. Los porcentajes de pedicelo, pericarpio, germen y endospermo harinoso y córneo se cuantificaron según Salinas y Vázquez (2006). El contenido de aceite en grano entero y tortillas se determinó por el método 7.044 (AOAC, 1984), y el de proteína en endospermo, grano entero y tortillas con el método 46-11 (AACC, 2000). Los contenidos de lisina y triptófano en endospermo, grano entero y tortillas, se cuantificaron con la metodología descrita por Galicia et al. (2009), y se expresaron en $g$ de aminoácido por $100 \mathrm{~g}$ de proteína. Los análisis de proteína, lisina y triptófano se realizaron en muestra seca y desengrasada.

\section{Calidad de nixtamal y tortillas}

La nixtamalización y elaboración de tortillas se hizo con la metodología descrita por Salinas y Vázquez (2006). El tiempo de cocción para cada muestra se asignó de acuerdo con el IF, como sigue: granos con IF entre 0 a $12 \%$ se dejaron 45 min en ebullición; de 13 a $37 \%$, 40 min; de 38 a $62 \%$, $35 \mathrm{~min}$; y de 63 a $87 \%$, $30 \mathrm{~min}$. El porcentaje de pericarpio retenido se midió en el nixtamal, mientras que las pérdidas de sólidos se midieron en el nejayote (agua de cocción) y en el agua de lavado del nixtamal (Salinas y Vázquez, 2006). Se cuantificó la humedad del nixtamal y tortillas con el método 44-10 (AACC, 2000). Se determinó también el rendimiento de masa y tortilla, expresados como $\mathrm{kg}$ de masa y tortilla por kg de maíz procesado, respectivamente. La fuerza de punción requerida para romper la tortilla, se obtuvo en un texturómetro TA.XT2i (Stable Micro Systems; Surrey, UK), con el método descrito por Arámbula et al. (2004), y se expresó en gramos-fuerza $\left(\mathrm{g}_{\mathrm{f}}\right)$. El porcentaje de reflectancia (color) se obtuvo en tortillas frías, a 2 y $24 \mathrm{~h}$ después de elaboradas y almacenadas a $4{ }^{\circ} \mathrm{C}$ en bolsas de 
polietileno; la calibración del reflectómetro Agtron se hizo con los mosaicos número10 y 52 .

\section{Análisis estadístico}

Los datos se analizaron conforme a un diseño experimental de bloques completos al azar con dos repeticiones. Los análisis de varianza, las pruebas de comparación de medias (Tukey) y los análisis de correlación simple se hicieron con el programa SAS para Windows, versión 9.

\section{RESULTADOS Y DISCUSIÓN}

Se encontraron efectos significativos $(\mathrm{P}<0.05)$ de localidad (L), híbrido (H) y de la interacción $\mathrm{H}$ x L, en la mayoría de variables medidas (Cuadro 1), diferencias que se deben a las condiciones agroclimáticas de los dos sitios y a la variabilidad genética entre los cuatro híbridos (Zepeda et al., 2009).

Cuadro 1. Cuadrados medios y significancia estadística para las características de grano y tortillas de cuatro híbridos de alta calidad proteinica ACP producidos en dos localidades, Santa Lucía, Edo. Méx y Tecamachalco, Puebla. 2003.

\begin{tabular}{|c|c|c|c|c|c|c|}
\hline Fuente de variación & Híbridos $(\mathrm{H})$ & Localidad (L) & $\mathrm{H} \times \mathrm{L}$ & Error & $\mathrm{R}^{2}$ & CV (\%) \\
\hline Grados de libertad & 3 & 1 & 3 & 8 & & \\
\hline Peso de cien granos & $28.53^{\star *}$ & $10.73^{* *}$ & $28.34^{* *}$ & 0.23 & 0.98 & 1.70 \\
\hline Índice de flotación & $271.92^{\star *}$ & $4579.90^{\star \star}$ & $412.01^{\star *}$ & 2.88 & 0.99 & 4.84 \\
\hline Peso hectolítrico & $13.21^{\star *}$ & $221.27^{\star \star}$ & $10.66^{\star *}$ & 0.05 & 0.99 & 0.30 \\
\hline Pedicelo & $0.47^{\star *}$ & $0.42^{\star \star}$ & $0.18^{\star *}$ & 0.01 & 0.97 & 5.37 \\
\hline Pericarpio & $0.21^{* *}$ & $1.25^{\star *}$ & $0.11^{\star *}$ & 0.01 & 0.95 & 1.79 \\
\hline Germen & $1.35^{\star *}$ & 0.4 & $1.44^{* *}$ & 0.17 & 0.86 & 3.55 \\
\hline Endospermo harinoso & 68.29 & $3280.99^{\star *}$ & $163.77^{\star}$ & 40.05 & 0.92 & 12.64 \\
\hline Endospermo córneo & 71.71 & $3292.46^{\star *}$ & $183.00^{*}$ & 38.31 & 0.92 & 20.36 \\
\hline Aceite en grano & $0.18^{\star *}$ & $3.51^{\star *}$ & $0.06^{* *}$ & 0.01 & 0.99 & 1.30 \\
\hline Aceite tortillas & $0.36^{* *}$ & 0.01 & $0.26^{\star *}$ & 0.01 & 0.96 & 3.86 \\
\hline Proteína en grano & $0.39^{* *}$ & $6.12^{\star \star}$ & $0.40^{\star *}$ & 0.02 & 0.98 & 1.30 \\
\hline Proteína en endospermo & $0.61^{*}$ & $13.14^{* *}$ & $1.34^{* *}$ & 0.10 & 0.96 & 4.03 \\
\hline Proteína en tortillas & $0.08^{\star}$ & $12.25^{\star *}$ & $0.60^{* *}$ & 0.02 & 0.99 & 1.28 \\
\hline Lisina en grano & $0.01^{* *}$ & $0.01^{* *}$ & $0.01^{* *}$ & 0.01 & 0.99 & 0.72 \\
\hline Lisina en endospermo & $0.01^{* *}$ & $0.01^{* *}$ & $0.01^{* *}$ & 0.01 & 0.99 & 1.43 \\
\hline Lisina en tortillas & $0.01^{* *}$ & $0.06^{\star *}$ & $0.01^{* *}$ & 0.01 & 0.99 & 1.27 \\
\hline Triptófano en grano & $0.01^{\star *}$ & $0.01^{\star *}$ & $0.01^{\star *}$ & 0.01 & 0.99 & 1.70 \\
\hline Triptófano en endospermo & 0.01 & $0.01^{\star *}$ & $0.01^{\star}$ & 0.01 & 0.94 & 6.62 \\
\hline Triptófano tortilla & $0.01^{* *}$ & $0.01^{\star *}$ & $0.01^{* *}$ & 0.01 & 0.99 & 1.63 \\
\hline Sólidos & $0.33^{* *}$ & $0.24^{\star *}$ & $0.14^{* *}$ & 0.01 & 0.98 & 1.76 \\
\hline Pericarpio retenido & $123.33^{*}$ & $1020.64^{\star}$ & 88.35 & 23.00 & 0.90 & 11.02 \\
\hline Humedad en nixtamal & $7.19^{* *}$ & $82.35^{\star *}$ & $3.71^{* *}$ & 0.07 & 0.99 & 0.55 \\
\hline Humedad en tortillas & $5.01^{* *}$ & $37.21^{\star *}$ & $2.16^{* *}$ & 0.07 & 0.99 & 0.63 \\
\hline Rendimiento de masa & 0.01 & 0.01 & $0.01^{* *}$ & 0.01 & 0.88 & 0.83 \\
\hline Rendimiento de tortillas & $0.01^{\star *}$ & $0.01^{\star *}$ & $0.01^{\star *}$ & 0.01 & 0.97 & 0.59 \\
\hline Fuerza de ruptura & $294.33^{* *}$ & $3856.41^{\star *}$ & $1765.63^{\star *}$ & 6.50 & 0.99 & 1.11 \\
\hline Color de grano & $16.50^{* *}$ & 1.00 & $7.5^{\star *}$ & 0.37 & 0.96 & 1.04 \\
\hline Color tortillas (2 h) & $360.41^{* *}$ & 4.00 & $44.16^{* *}$ & 0.81 & 0.99 & 1.03 \\
\hline Color tortillas $(24 \mathrm{~h})$ & $131.34^{\star *}$ & $17.01^{\star *}$ & $8.01^{\star}$ & 1.58 & 0.97 & 1.54 \\
\hline
\end{tabular}




\section{Características físicas del grano}

La significancia en la interacción $\mathrm{H} \times \mathrm{L}(\mathrm{P} \leq 0.01)$ muestra que ambos factores influyeron conjuntamente en las características físicas de los granos (Cuadro 1). Como el peso de 100 granos (PCG) estima el tamaño del grano (Billeb y Bressani, 2001), los valores de PCG menores de 38 g corresponden a granos pequeños. Todos los maíces ACP resultaron de grano pequeño, pero los sembrados en SLM registraron un mayor PCG (29.3 g) respecto a los de TP (27.7 g); destacó el híbrido 'H-149C' por haber registrado el mayor PCG en SLM. En TP los híbridos fueron más uniformes en cuanto a PCG (Cuadro 2). Tal diferencia entre sitios se atribuye a una menor temperatura ambiental en SLM $\left(<25^{\circ} \mathrm{C}\right)$ durante el llenado del grano, ya que en TP fue superior a $25^{\circ} \mathrm{C}$ (CONAGUA, 2011). De acuerdo con Rincón et al. (2006), por cada grado centígrado $\left({ }^{\circ} \mathrm{C}\right)$ que se incrementa la temperatura por encima del óptimo (25 ${ }^{\circ} \mathrm{C}$ ), se reduce en 3 a $4 \%$ el rendimiento del grano, debido principalmente a la disminución en el número de gránulos de almidón. El incremento en la temperatura también aumenta la tasa de crecimiento del grano, pero el periodo de llenado de éste disminuye, por lo que el peso individual de los granos se reduce (Muchow, 1990).

El peso hectolítrico $(\mathrm{PH})$ de los maíces sembrados en $\mathrm{TP}$ fue superior que los producidos en SLM $(\mathrm{P} \leq 0.05)$, tanto en los híbridos ACP $\left(80.2 \mathrm{~kg} \mathrm{hL}^{-1}\right)$ como en el testigo(Cuadro 2). Este comportamiento se atribuye a la mayor temperatura y menor precipitación ocurridas durante la etapa de llenado del grano en TP, según lo reportado por Yang et al. (2000). En cuanto a la dureza del grano, se encontró que los más duros (menor IF) fueron los cosechados en TP, en tanto que los cosechados en SLM fueron suaves e intermedios. De acuerdo con Fox y Manley (2009), la dureza del grano es una característica hereditaria que es afectada por los componentes químicos del grano (principalmente almidón y proteína), los cuales son fuertemente influenciados por las condiciones ambientales. Los materiales con mayor peso hectolítrico fueron los de granos más duros $(r=-0.96$; $\mathrm{P} \leq 0.01$ ), en concordancia con lo informado por Dorsey et al. $(1991)(\mathrm{r}=-0.81 ; \mathrm{P} \leq 0.01)$.

Con respecto a los componentes del grano, los maíces de TP registraron mayor porcentaje de pedicelo y germen y menos pericarpio que los de SLM (Cuadro 2). Todos los componentes variaron entre híbridos, y el 'H-145C' fue el de menos pericarpio y más germen en ambas localidades. El porcentaje de germen de los híbridos de TP fue superior al testigo de endospermo normal, lo que podría influir en una mayor rancidez oxidativa en las harinas, pero el germen aporta mayor contenido energético y mejora la calidad nutricional de los productos elaborados (Billeb y Bressani, 2001). Los materiales cultivados en TP tuvieron mayor porcentaje de endospermo vítreo que los de SLM, y por ello durante la nixtamalización la absorción de agua de estos maíces fue más lenta, como demostraron Billeb y Bressani (2001), lo que se reflejó en una baja humedad de nixtamal (Cuadro 4). En SLM el híbrido 'H-143C' registró porcentajes de endospermo harinoso y vítreo semejantes a los del testigo, variables que correlacionaron con el índice de flotación $(\mathrm{r}=0.88 ; \mathrm{P} \leq 0.01)$.

El ambiente no afectó el color del grano (Cuadro 1). Todos los híbridos ACP registraron porcentajes de reflectancia iguales o superiores al valor $(55 \%)$ establecido por la industria de harina nixtamalizada como aceptable para su proceso (Vázquez et al., 2011). Destacó el híbrido 'H-149C' por tener el grano más blanco (mayor reflectancia) en ambas localidades (Figura 1). En los dos ambientes estudiados los híbridos ACP presentaron una variación amplia en las características físicas del grano. No obstante, de acuerdo con las especificaciones requeridas por una industria procesadora (Vázquez et al., 2011), a saber: reflectancia $\geq 55$ $\%$; dureza $\leq 20 \%$ de flotantes; y endospermo vítreo $\geq 48 \%$, los híbridos 'H-147C' y 'H-149C' de TP cumplen con tales requisitos, como se muestra en el Cuadro 2 . El resto de los híbridos de TP, así como 'H-143C' y 'H-147C' evaluados en SLM, cumplieron con las especificaciones de la industria de la masa y la tortilla (NMX-034, 2002).

\section{Calidad proteínica del grano}

Los híbridos ACP sembrados en TP registraron mayores contenidos de aceite en grano y tortillas (4.8 y $2.5 \%$, respectivamente) que los de SLM (3.8 y $2.4 \%$ ) (Cuadro 3). Las pérdidas de aceite ocurridas durante la nixtamalización fueron en promedio de $1.75 \%$, debido a su saponificación con el hidróxido de calcio $\left(\mathrm{Ca}(\mathrm{OH})_{2}\right)$ del agua de cocción durante la nixtamalización (Martínez et al., 2001).

Los híbridos ACP de SLM presentaron mayor contenido de proteína en grano, endospermo y tortillas, que los de TP (Cuadro 3). El contenido de proteína cruda total en grano varió de 9.1 a $11.5 \%$, que son valores superiores a los encontrados (7.31 a $9.21 \%$ ) por Serna et al. (2008) en 14 híbridos ACP y al $7.5 \%$ encontrado por Rojas et al. (2008) en el híbrido ACP 'H-368C'. De acuerdo con Mittelmann et al. (2003), los factores ambientales que más afectan el contenido de proteína en maíz son la temperatura y la disponibilidad de agua y nitrógeno en el suelo. Considerando que la temperatura media en TP es similar a la de SLM y que en ambos sitios no hubo restricciones de fertilización, el contenido mayor de proteína en los genotipos de SLM se explica por la mayor disponibilidad de agua en SLM durante el desarrollo del grano. 

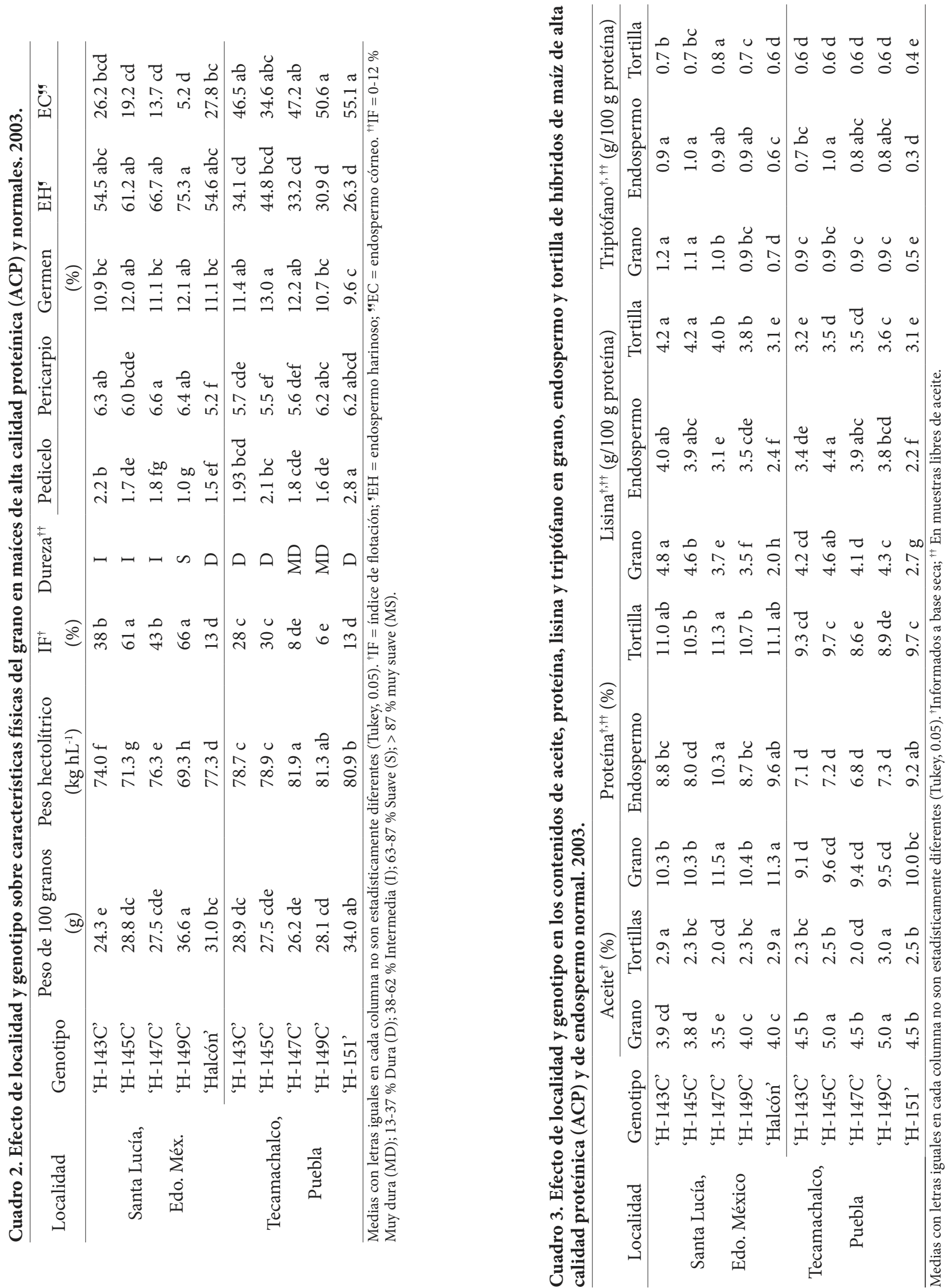


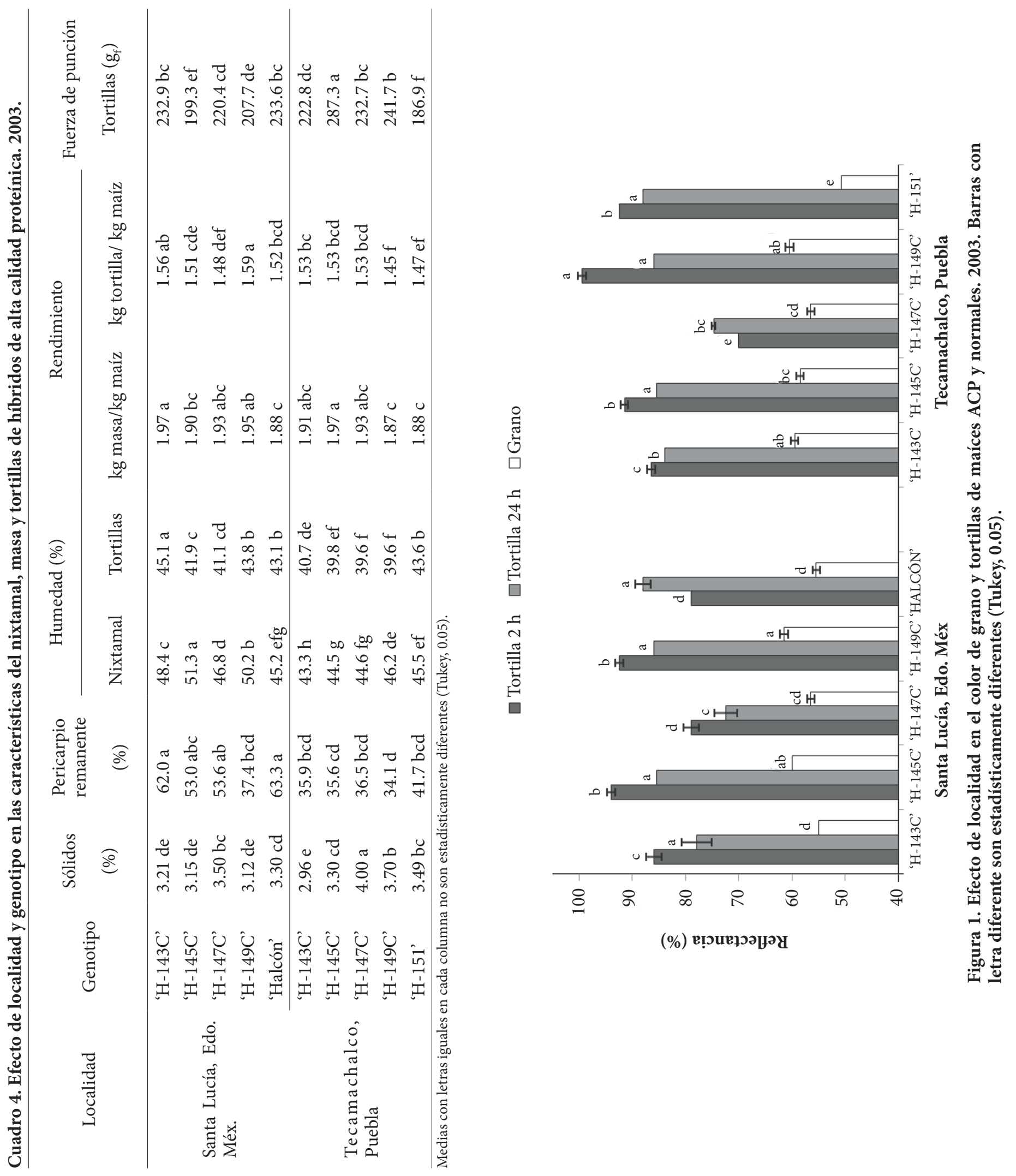


Los maíces ACP se consideran de alta calidad proteínica debido a que son buenos aportadores de lisina y triptófano, dos aminoácidos esenciales que son limitantes en los maíces de endospermo normal. Los granos de maíces ACP de este estudio contenían entre 3.528 y 4.798 g de lisina y entre 0.869 y $1.178 \mathrm{~g}$ de triptófano por $100 \mathrm{~g}$ de proteína. Dichos contenidos resultaron superiores a los testigos de endospermo normal y a los informados en otros maíces ACP (Melesio et al., 2008). En SLM el endospermo de los maíces ACP tuvo en promedio $50.2 \%$ más lisina que el testigo de endospermo normal, y el de los maíces de TP tuvo en promedio $74.5 \%$ más lisina que el testigo respectivo (Cuadro 3). Estos valores de lisina en endospermo son comparables a los informados por Habben et al. (1994), en otros maíces ACP. En cuanto al triptófano en grano y endospermo, en los híbridos ACP se sintetizó desde 33.9 hasta más de $100 \%$ del encontrado en los testigos (Cuadro 3). Incrementos similares de triptófano ya se habían encontrado en algunos maíces ACP del trópico (Mendoza et al., 2006).

Durante el procesamiento del maíz por nixtamalización, molienda y cocción de las tortillas, el contenido de lisina y su biodisponibilidad pueden verse afectados. En este estudio, , en SLM las pérdidas de lisina del grano a la tortilla fueron de 7 a $13 \%$ en promedio, y en TP de 15 a $25 \%$ (Cuadro 3), menores a las reportadas (36\%) por Rojas et al. (2008). La transformación a tortillas ocasionó pérdidas promedio de triptófano entre $26.7 \%$ en SLM y de $34.2 \%$ en TP, valores que fueron mayores a los informados (14.9\%) por Ortega et al. (1986) en otro híbrido de maíz ACP. Las pérdidas de ambos aminoácidos se deben a su disminución en la fracción albúminas + globulinas (rica en lisina y triptófano), que se dan durante el proceso de nixtamalización y posterior tiempo de reposo (Rojas et al., 2008). Si se considera el contenido actual de lisina y triptófano en las tortillas hechas con los híbridos estudiados, se tendría una proteína que cumple en su perfil con 66 a $89 \%$ de la lisina y con 89 a más del $100 \%$ del triptófano requeridos por los niños entre 3 y 10 años de edad (WHO, 2007). Sin embargo, no toda la lisina queda biodisponible en las tortillas, tal como mencionan Rojas et al. (2008).

La mejor calidad proteínica de los maíces ACP se debe a que en su endospermo se sintetiza mayor cantidad de albúminas y globulinas, proteínas ricas en lisina y triptófano, en tanto que las prolaminas (zeínas) que poseen menor contenido de esos aminoácidos, se reducen (Gutiérrez et al., 2008). La proteína del maíz normal tiene menor calidad nutricia porque su endospermo contiene entre 50 y $70 \%$ de prolaminas. Aunado a lo anterior, las mejores condiciones climatológicas y el control de la polinización en SLM pueden explicar la mejor calidad proteínica de los maíces ACP cultivados en esta localidad, como propusieron
Gutiérrez et al. (2008).

\section{Calidad de nixtamal y tortillas}

Las pérdidas de sólidos en el agua de cocimiento (nejayote) fueron estadísticamente iguales entre localidades y entre híbridos ACP. Los valores encontrados (Cuadro 4) marcaron menos pérdidas que las establecidas en la norma NMX-034 (2002). El nixtamal preparado con los híbridos ACP de SLM retuvo más pericarpio (51.5\%) que los de TP (35\%). Esto pudiera estar relacionado con la menor dureza del grano, puesto que el nixtamal y las tortillas de los híbridos de SLM registraron mayor porcentaje de humedad (49.2 y $43.0 \%$, respectivamente) que los de TP (44.7 y $40 \%)$. Los granos de dureza intermedia-suave fueron los que mayor cantidad de agua absorbieron $(\mathrm{r}=0.8$; $\mathrm{P} \leq 0.01)$ durante la nixtamalización, debido a que la fracción harinosa del endospermo posee mayor cantidad de amilopectina que la fracción vítrea (Dombrink y Knutson, 1997) y la amilopectina absorbe más rápido el agua que la amilosa (Ansari et al., 2010).

El mayor porcentaje de humedad de las tortillas de SLM se asoció con su mayor rendimiento de masa (1.94) y de tortillas $(1.54 \%)$. Estas tortillas requirieron una menor fuerza de punción (207.7 $\mathrm{g}_{\mathrm{f}}$ ) para romperse, porque fueron de textura más suave que las de TP (Cuadro 4). Un comportamiento similar fue observado para maíces de endospermo normal por Vázquez et al. (2011).

El mayor rendimiento de tortillas de los maíces ACP de SLM se debe a que se solubilizó más cantidad de pericarpio en la masa, que actúa como goma natural, lo que favorece la retención de humedad y, por tanto, la suavidad de las tortillas (Martínez et al., 2001). En los maíces ACP el rendimiento de tortillas fue alto en las dos localidades (1.5 kg de tortillas/1.0 kg de maíz), lo que indica que esta variable depende más del tiempo de nixtamalización que de la dureza del grano. Lo anterior también indica que los maíces ACP de dureza intermedia-suave son una excelente opción para el proceso doméstico y el industrial de la masa-tortilla, porque requieren menos combustible para su nixtamalización y menos fuerza para su molienda y el moldeado de la masa, especialmente cuando se elaboran manualmente.

El color del grano se correlacionó positivamente con el color de las tortillas recién elaboradas $(r=0.70 ; \mathrm{P} \leq$ $0.01)$ y 24 h después $(r=0.82 ; \mathrm{P} \leq 0.01)$. El porcentaje de reflectancia en grano y tortillas a las $2 \mathrm{~h}$ de elaboradas, no mostró efecto de localidad (Cuadro 1), pues en ambas localidades las tortillas fueron de color crema brillante. En las tortillas almacenadas $(24 \mathrm{~h})$ el color se redujo por efecto de localidad y por tipo de híbrido, ya que las de 
SLM fueron más oscuras (80.5 \%) que las de TP (82.6 $\%)$, comportamiento que podría deberse a una mayor concentración de fenoles libres y totales en el pericarpio y el endospermo de los maíces, como mencionaron Salinas et al. (2007). Las tortillas de color más claro se produjeron con el grano del híbrido 'H-149C' de SLM y TP (Figura 1), tanto recién elaboradas $(2 \mathrm{~h})$ como almacenadas $(24 \mathrm{~h})$. Las más oscuras fueron las del híbrido 'H-147C', a 2 y 24 h después de elaboradas en ambas localidades. Con los maíces ACP de TP, que fueron los más duros y cuyo nixtamal desprendió más pericarpio, se produjeron las tortillas con menos cambio de color durante el almacenamiento.

\section{CONCLUSIONES}

Los cuatro híbridos de maíz de alta calidad proteínica (ACP) desarrollados para los Valles Altos de México, resultaron con modificaciones en las características físicas de sus granos, la calidad de su proteína y la de sus tortillas, por efecto del medio ambiente y del genotipo. El ambiente de Santa Lucía (SLM) propició un grano más suave, que se correlacionó con un mayor contenido de proteína, lisina y triptófano. En Tecamachalco (TP) los granos fueron de textura más dura, con mayor contenido de aceite y menor contenido de proteína. En ambas localidades la calidad de la proteína de las tortillas fue superior a la de los híbridos de endospermo normal. Las tortillas hechas con los híbridos ACP estudiados cumplen en su perfil con 66 a $89 \%$ de la lisina y con 89 a más de $100 \%$ del triptófano requerido por los niños entre 3 y 10 años de edad. Así, bajo diferentes condiciones ambientales es posible producir grano de maíces ACP con muy buenas características físicas, nutricionales y de procesamiento, que resuelva las necesidades de la demanda doméstica, de la masa-tortillas y de harina nixtamalizada.

\section{BIBLIOGRAFÍA}

AACC, American Association of Cereal Chemists (2000) Approved Methods of the American Association of Cereal Chemists. 10th ed. The Association. St. Paul, MN. pp:69-124.

Ansari O, M Baga, R N Chibbar, N Sultana, N K Howes (2010) Analysis of starch swelling power in Australian breeding lines of hexaploid wheat (Triticum aestivum L.). Field Crops Res. 115:171-178.

AOAC, Association of Official Analytical Chemists (1984) Official Methods of Analysis the AOAC. 13th ed. The Association. Washington, D.C. pp:132-133.

Arámbula V G, J A Méndez A, J González H, E Gutiérrez A, E Moreno M (2004) Evaluación de una metodología para determinar características de textura de tortilla de maíz (Zea mays L.). Arch. Latinoam. Nutr. 54:216-222.

Ávila P M A, J L Arellano V, J Virgen V, A J Gámez V (2009) H-52, híbrido de maíz para Valles Altos de la Mesa Central de México. Agric. Téc. Méx. 35:237-240.

Billeb S A C, R Bressani (2001) Características de cocción por nixtamalización de once variedades de maíz. Arch. Latinoam. Nutri. 51:86-94.

Chávez V A, M Muñoz C (2004) La Tortilla de Alto Valor Nutritivo. McGraw-Hill. México, D.F. 110 p.

CONAGUA, Comisión Nacional del Agua (2011) Normales Climatológicas por Estación. Sistema Meteorológico Nacional.
Disponible en http://smn.cna.gob.mx/. (Agosto 2011).

Dombrink K M A, C A Knutson (1997) A study of maize endosperm hardness in relation to amylose content and susceptibility to damage. Cereal Chem. 74:776-780.

Dorsey R C, C R Hurburgh J, L A Johnson, S R Fox (1991) Relationships among maize quality factors. Cereal Chem. 68:602-605.

Fox G, M Manley (2009) Hardness methods for testing maize kernels. J. Agric. Food Chem. 57:5647-5657

Galicia L, E Nurit, A Rosales, N Palacios R (2009) Maize Nutrition Quality and Plant Tissue Analysis Laboratory. Laboratory Protocols. CIMMYT. México, D.F. 42 p.

Gutierrez R A, M P Scott, O R Leyva, M Menz, J Betrán (2008) Phenotypic characterization of quality protein maize endosperm modification and amino acid contents in a segregating recombinant inbred population. Crop Sci. 48:1714-1722.

Habben J E, G L Moro, B G Hunter, B R Hamaker, B A Larkins (1994) Characterization of the proteins that define the nutritional quality of maize endosperm: In: Quality Protein Maize: 1964-1994. B A Larkins, E T Mertz (eds). EMBRAPA/CNPMS, Sete Lagoas, MG, Brazil. pp:121-132

Martínez B F, H E Martínez F, E Sanmartín M, F Sánchez S, Y K Chang, D Barrera A, E Rios (2001) Effect of the components of maize on the quality of masa and tortillas during the traditional nixtamalisation process. J. Sci. Food Agric. 81:1455-1462.

Melesio C J L, R E Preciado O, A D Terrón I, M G Vázquez C, P Herrera M, C A Amaya G, S O Serna S (2008) Potencial productivo, propiedades físicas y valor nutrimental de híbridos de maíz de alta calidad proteínica. Agric. Téc. Méx. 34:225-233.

Mendoza E M, E A Enríquez, J M Juárez G, C Mosqueda V, L Latournerie M, G Castañón N, A López B, E Moreno M (2006) Contenido de lisina y triptófano en genotipos de maíz de alta calidad proteica y normal. Univ. Ciencia 22:153-161.

Mittelmann A, J B Miranda F, G J M Monteiro L, C Hara K, R Takao T (2003) Potential of the ESA23B maize population for protein and oil content improvement. Sci. Agric. 60:319-327.

Muchow R C (1990) Effect of high temperature on grain-growth in fieldgrown maize. Field Crops Res. 23:145-158.

Norma Mexicana NMX-FF-034/1-SCFI-2002 (2002) Productos alimenticios no industrializados para consumo humano-CerealesParte I: Maíz blanco para proceso alcalino para tortillas de maíz y productos de maíz nixtamalizado-Especificaciones y métodos de prueba. SAGARPA-Dirección General de Normas. México, D.F. $18 \mathrm{p}$.

Ortega E I, E Villegas, S K Vasal (1986) A comparative study of protein changes in normal and quality protein maize during tortilla making. Cereal Chem. 63:446-451.

Polanco J A, T Flores M (2008) Bases para una Política de I\&D e Innovación de la Cadena de Valor del Maíz. Foro Consultivo Científico y Tecnológico. México, D.F. 244 p.

Rincón T J A, S Castro N, J A López S, A J Huerta, C Trejo L, F Briones E (2006) Temperatura alta y estrés hídrico durante la floración en poblaciones de maíz tropical. Rev. Inter. Bot. Exp. 75:31-40.

Rojas M I, E Gutiérrez, M E Cortés A, A Falcón, R Bressani, A Rojas, C Ibarra, J L Pons H, S H Guzmán M, A Cornejo V, M E Rodríguez (2008) Analysis of quality protein changes in nixtamalized QPM flours as a function of steeping time. Cereal Chem. 85:409-416.

Salinas M Y, J J López R, G B González F, G Vázquez C (2007) Compuestos fenólicos del grano de maíz y su relación con el oscurecimiento de masa y tortilla. Agrociencia 41:295-305.

Salinas M Y, G Vázquez C (2006) Metodologías de Análisis de la Calidad Nixtamalera-Tortillera en Maíz. Folleto Técnico No. 23. INIFAP. México, D.F. 91 p.

Serna S S O, C A Amaya G, P Herrera M, J L Melesio C, R E Preciado O, A D Terron I, G Vazquez C (2008) Evaluation of the limecooking and tortilla making properties of quality protein maize hybrids grown in Mexico. Plant Foods Human Nutr. 63:119-125.

Vázquez C G, S García L, Y Salinas M, D J Bergvinson, N Palacios R (2011) Grain and tortilla quality in landraces and improved maize grown in the highlands of Mexico. Plant Foods Human Nutr. 66:203-208.

WHO, World Health Organization (2007) Protein and amino acid requirements of infants and children: In: Protein and Amino Acid Requirements in Human Nutrition. Report of a Joint WHO/FAO/ UNU Expert Consultation. WHO Technical Report Series 935. 
Geneva. pp:161-184.

Yang P, R J Shunk, A E Haken, Y X Niu, S H Zou, P Buriak, S R Eckhoff, M

E Tumbleson (2000) Yield, protein content, and viscosity of starch from wet-milled corn hybrids as influenced by environmentally induced changes in test weight. Cereal Chem. 77:44-47.

Zepeda B R, A Carballo C, C Hernández A (2009) Interacción genotipoambiente en la estructura y calidad del nixtamal-tortilla del grano en híbridos de maíz. Agrociencia 43:695-706. 